\title{
Cigarros eletrônicos: sim ou não?
}

\author{
Electronic Cigarettes: yes or no?
}

Brose LS, Brown J., Hitchman SC, McNeill A. Perceived relative harm of electronic cigarettes over time and impact on subsequent use. A survey with 1-year and 2-year follow-ups. Drug Alcohol Depend. 2015; S0376-8716(15):01696-8.

\author{
Bruna Maria Rodrigues Vilardi* \\ TAISA MARIA RODRIGUES VILARDI* \\ Doutoras em Patologia- FOB- USP e Docentes do Departamento de \\ Diagnóstico Bucal da Faculdade de Odontologia de Lins - UNIMEP
}

Mundialmente, o tabagismo tem sido uma expressiva causa de morte. Os componentes do cigarro, hidrocarbonetos, nitrosaminas, favorecem a ação deletéria sobre a mucosa bucal, quadro agravado pelo etilismo. E ainda, há medicamentos que interagem com as substâncias presentes no cigarro, e sofrem alterações bioquímicas.

Atualmente, há um crescimento na comercialização de métodos alternativos para deixar o tabagismo. Os cigarros eletrônicos foram criados para ser um desses métodos. A cada ano verifica-se um aumento significante no uso desses dispositivos. Os pesquisadores acreditam que esses cigarros são bem aceitos, por imitar os cigarros tradicionais, proporcionando, durante o seu uso, movimentos e padrões de comportamento ao usuário semelhantes aos do hábito de fumar. Dessa forma, acredita-se que auxiliem na cessação do tabagismo e na sensação de alívio dos sintomas de abstinência melhor do que os adesivos de nicotina, considerados até esta ocasião a melhor opção de tratamento.

Os cigarros eletrônicos também são conhecidos como e-cigarros/e-cigarettes ou Electronic Nicotine Delivery Systems (ENDS). Esse produto vem sendo comercializado, inclusive, por não apresentar restrições de uso em locais públicos. Os usuários de e-cigarros são conhecidos como vapers. Esses dispositivos são compostos por bocal, circuito microelétri- co, vaporizador, uma bateria de lítio recarregável, um atomizador, onde o líquido é armazenado e evaporado por meio do mecanismo de ativação da bateria. O manuseio do dispositivo é semelhante aos cigarros convencionais: no momento da tragada, o vaper aciona, por meio da pressão sobre um botão, um ciclo inicialmente de aquecimento, até atingir o ponto de ebulição do líquido, para que seja transformado em vapor. Ao final da aspiração, o usuário para de pressionar o botão, expira o vapor, ocorre o resfriamento, e o dispositivo só voltará a aquecer quando tragado novamente.

Tem sido observado que os fabricantes dos líquidos para cigarros eletrônicos (e-líquidos) não informam verdadeiramente a sua composição. Segundo avaliações químicas, os e-líquidos contêm nicotina, glicerina, propileno glicol, água e flavorizantes. Alguns vapers fazem o uso dos cigarros eletrônicos para ingestão de substâncias como Cannabis, ervas, aromatizantes e vodca. Assim como nos cigarros tradicionais, a nicotina é um componente constante nos e-líquidos. A variação encontrada é de 16 até $22 \mathrm{mg} / \mathrm{ml}$, fator preocupante devido à toxicidade dessa substância, principalmente sobre a mucosa bucal. Tanto os vapers quanto os fumantes passivos são expostos a esses aerossóis.

Efeitos adversos provocados pelo uso dos e-cigarros têm sido descritos, por exemplo, irritação na mucosa da boca e/ou na garganta, 
tosse seca, redução da qualidade de algumas atividades pulmonares. Entretanto, usuários com tontura, náuseas e dores de cabeça, relataram que as sensações diminuíram com a continuação do uso. Uma questão que abrange a tolerabilidade desenvolvida, que ocasionalmente se desenvolve com algumas substâncias. Estudos sugerem que os aerossóis dos e-cigarros podem ser menos tóxicos do que a fumaça do cigarro, porém, são informações inconclusivas.

Outro aspecto que deve ser abordado é que, mesmo que indiretamente, os cigarros eletrônicos são danosos à saúde, devido ao impacto sobre o ambiente, já que seus compostos e método de fabricação produzem mais sustâncias poluentes em comparação com a fabricação do cigarro tradicional.

Até o presente momento, a maioria dos vapers é de jovens do gênero masculino.
A maior parte dos usuários de e-cigarros começou a utilizá-los com a intenção de abandonar o tabagismo, mas não o fizeram. O segundo tipo mais comum de vapers são aqueles que passaram a fumar os cigarros eletrônicos por modismo.

Órgãos governamentais têm dificuldades em classificar os cigarros eletrônicos como tabaco ou medicina auxiliar no uso de nicotina. Além disso, há ausência de fiscalização e normas sobre esses dispositivos, fato que tem favorecido o aumento do número de usuários e de tipos de produtos comercializados. E ainda, os componentes dos e-cigarros, como os refis ou cartuchos, também apresentam fácil acesso e venda livre de qualquer tipo de controle ou inspeção.

Submetida em: 19-11-2015

Aceita em:19-11-2015 